\title{
Epidemiological Distribution of Reported West Nile cases in Houston, Texas, 2014-2017
}

\section{Razina Khayat, Alex Nguyen, Sudipa Biswas, Hafeez Rehman, Kirstin Short, Najmus Abdullah}

Informatics, City of Houston, Houston, Texas, United States

Objective

To demonstrate an overview of the epidemiological and clinical distribution of reportable West Nile cases in Houston, Texas, from 2015-2017.

\section{Introduction}

West Nile virus (WNV) is considered the leading cause of domestically acquired arboviral disease and is spread through mosquitoes. In general, the majority of the cases are asymptomatic. One in five people infected will display mild symptoms like fever, headache, body ache, nausea, and vomiting. Only about 1 in 150 people infected will develop serious neurologic complications such as encephalitis and meningitis. According to CDC, in 2017, there were 133 confirmed cases including 5 deaths and 14 presumptive blood donors reported in the State of Texas. Out of the confirmed cases, there were 85 neuroinvasive and 48 non- neuroinvasive disease cases.

\section{Methods}

Data were extracted from Houston's Electronic Disease Surveillance System (HEDSS) from January 1, 2014, to December 31, 2017. A total of 45 confirmed cases are included in this analysis to examine the epidemiologic characteristics of the WNV cases.

A confirmed case is an illness with onset of acute focal limb weakness and an MRI showing a spinal cord lesion largely restricted to gray matter and spanning one or more spinal segments.

\section{Results}

Among the confirmed cases, $67 \%$ of were males. Age group 60 and above (47\%) had the highest proportion of WNV cases. Whites (26\%) represented the highest number of confirmed cases followed by Hispanics (24\%).

Seventy six percent of the cases were hospitalized. Non-neuroinvasive clinical presentations found among confirmed WNV cases were fever (94\%), headache (76\%) followed by chills and rigors $(68 \%)$. Among the neuroinvasive presentations, altered mental status had the highest proportion (24\%), followed by stiff necks (18\%), Ataxia (12\%), and seizure (9\%).

\section{Conclusions}

WNV is mostly prevalent in White male adults over 60 years of age, with majority of cases have common neuroinvasive symptoms like altered mental status, stiff necks, and Ataxia. For non-neuroinvasive cases clinical symptoms were fever, headache, chills and rigors.

WNV infection is a markedly underreported disease as most of the infected people do not seek medical care due to mild or no symptoms. Currently there are no specific treatments available. Thus, continued monitoring and surveillance activities are warranted for prevention and control of WNV complications as well as decreasing the risk of infection.

\section{Acknowledgement}

We thank the flollowing agencies for providing data for this study:

Texas Department of State Health Services.

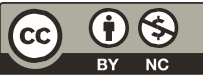

ISDS Annual Conference Proceedings 2019. This is an Open Access article distributed under the terms of the Creative Commons AttributionNoncommercial 4.0 Unported License (http://creativecommons.org/licenses/by-nc/3.0/), permitting all non-commercial use, distribution, and reproduction in any medium, provided the original work is properly cited. 
Houston Health Department, Diivision of Disease Prevention and Control. Houston Electronic Disease Surveillance System.

\section{References}

1. CDC. West Nile Virus [Internet]. Atlanta: Center for Disease Control and Prevention (CDC), National Center for Emerging and Zoonotic Infectious Diseases (NCEZID), and Division of Vector-Borne Diseases (DVBD); Last reviewed: September 19, 2018. Available from: https://www.cdc.gov/westnile/index.html 